Supplementary Information

\title{
Real-time facile detection of the WO3 catalyst oxidation state under microwaves using a resonance frequency
}

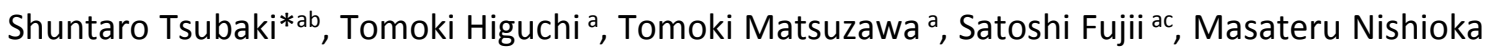
d, Yuji Wada ae

a School of Materials and Chemical Technology, Tokyo Institute of Technology, E4-3, 2-12-1, Ookayama, Meguro-ku, Tokyo 152-8552, Japan.

b PRESTO, Japan Science and Technology Agency (JST), 4-1-8 Honcho, Kawaguchi, Saitama 3320012, Japan

c Department of Information and Communication Systems Engineering, National Institute of Technology Okinawa College, 905 Henoko, Nago-shi, Okinawa, 905-2192, Japan.

${ }^{d}$ National Institute of Advanced Industrial Science and Technology, 4-2-1, Nigatake, Miyaginoku, Sendai, 983-8551, Japan.

e Institute of Innovative Research, Tokyo Institute of Technology, 4259 Nagatsuta-cho, Midoriku, Yokohama, Kanagawa 226-8503 Japan.

*Corresponding author: E-mail; shuntaro.tsubaki@gmail.com, tsubaki.s.aa@m.titech.ac.jp, Tel: $+81-3-5734-3418$ 

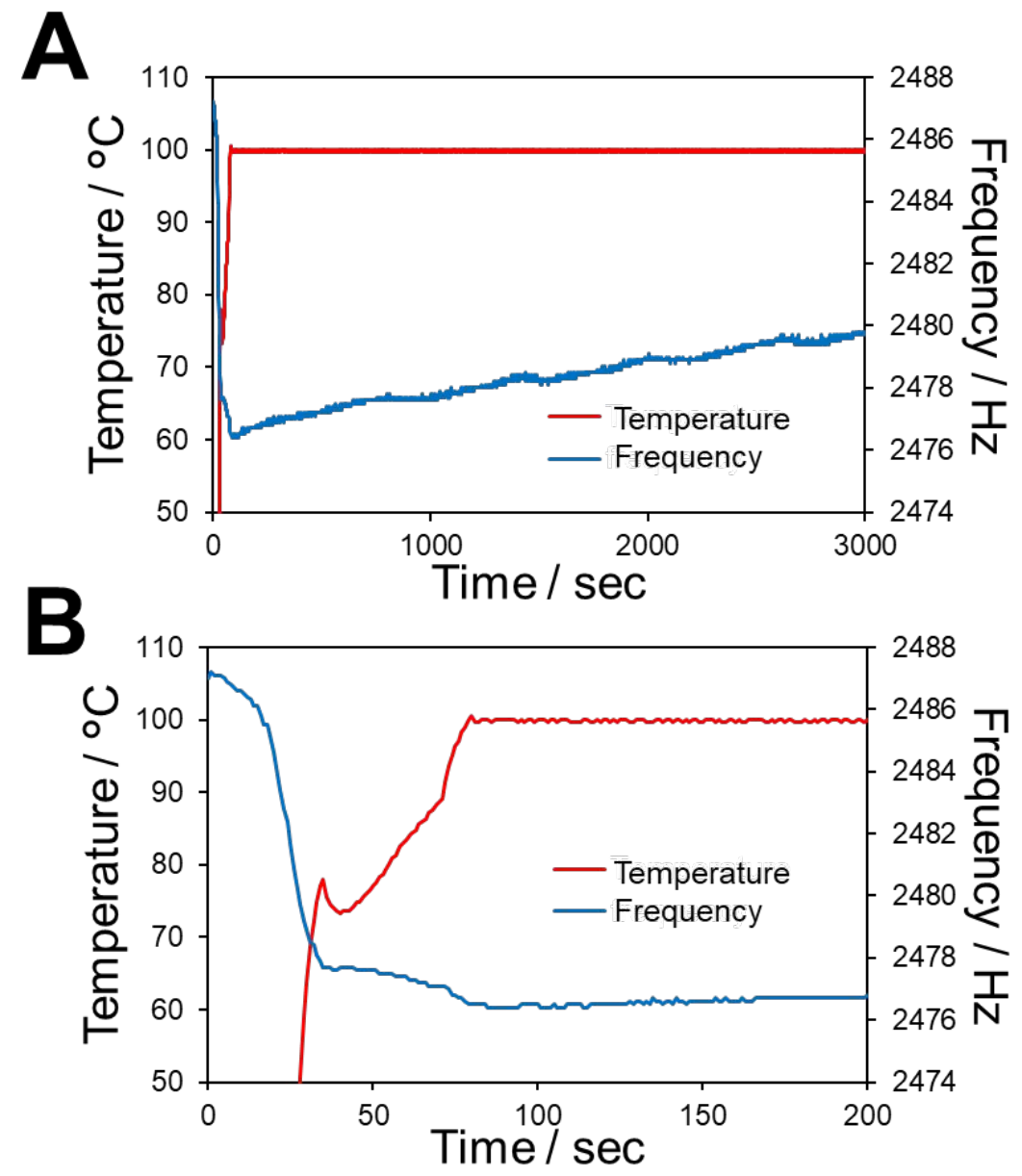

Figure S1. Typical profiles of temperature and resonance frequency during $\mathrm{MW}$ heating of $\mathrm{WO}_{3}$ under air. The temperature was maintained at $100^{\circ} \mathrm{C}$ by PID. (A) Overall profile. (B) Expanded figure during heating. 


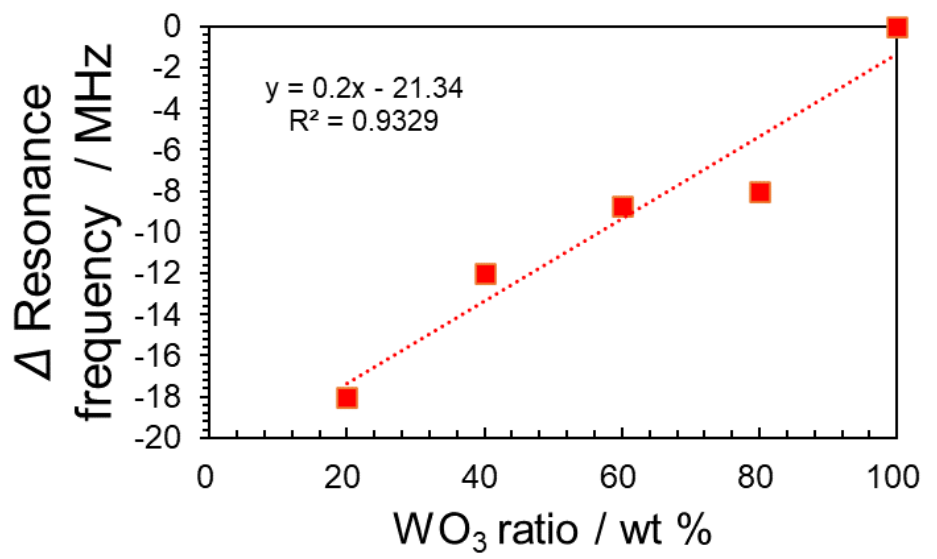

Figure S2. Shift in resonance frequency depending on the different ratios of $\mathrm{WO}_{2}$ and $\mathrm{WO}_{3}$. Change in resonance frequency was calculated from the difference of $f_{\mathrm{WO}_{3}}$ and $f_{\left(\mathrm{WO}_{3}+\mathrm{WO}_{2}\right)}$. 

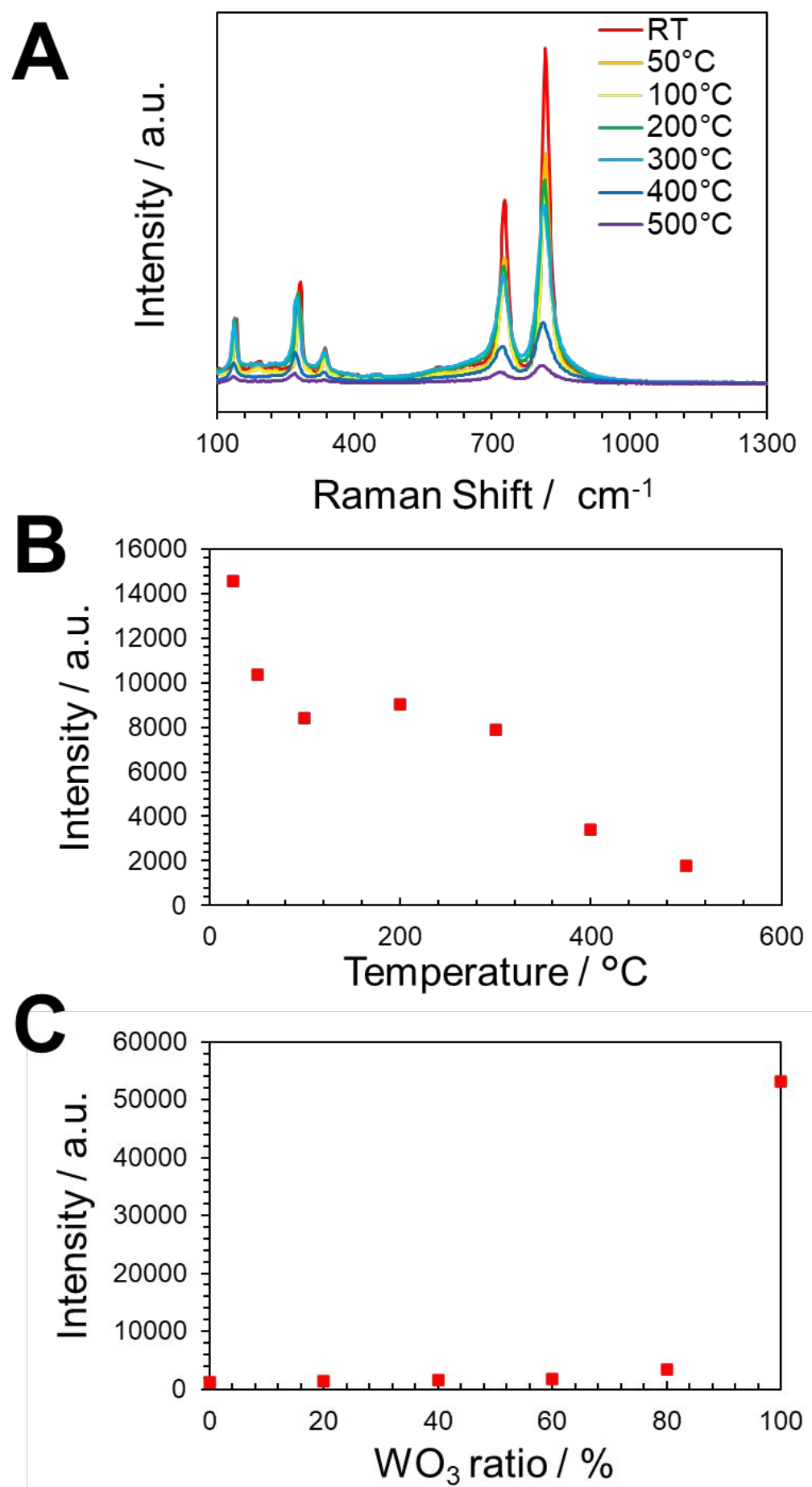

Figure S3. (A) Temperature dependent Raman spectra of $\mathrm{WO}_{3}$. Intensity of Raman peak of $\mathrm{WO}_{3}$ at $817 \mathrm{~cm}^{-1}$ depending on the (B) temperature varying from room temperature to $500{ }^{\circ} \mathrm{C}$ (by conventional heating) and (C) different ratios of $\mathrm{WO}_{2}$ and $\mathrm{WO}_{3}$. 